\title{
Economical mechanism for the reform of regional heat supply systems
}

\author{
Y. Munts \\ Ural Federal University, Russia
}

\begin{abstract}
We offer a mechanism to reform the regional heat supply system, which is based upon the principles of economic efficiency of implementing investment projects in heat supply, as well as on the complex approach to the reformation and availability of the heat supply services for socially unprotected consumers. The basis of the mechanism is the methodology for assessing the economic efficiency of complex programs of heat supply reformation in municipal institutions, which includes both the projects of resource and energy saving in heat supplying companies and the projects of reducing heat energy consumption for the end consumer. We have developed the mathematic model that enables the assessment of the possibility and feasibility of attracting private investment to the complex programs given. We have made an economic assessment of the feasibility of the complex program for a concrete municipal institution, which aims at reducing payments for the consumer of heat energy.

Keywords: heat supply, reformation, investments, efficiency.
\end{abstract}

\section{Problems of reformation of the heat supply system}

The main aim of the concept of reformation of the communal services system in general, and the system of heat supply in municipal institutions, in particular, is to raise the efficiency of the given systems in operation with simultaneous reduction in communal payments for the public.

In the chapter 'Heat Supply' in the Power System Strategy of the Russian Federation up to 2030 [1] it is defined that the strategic aims of developing the sphere of heat supply are as follows:

- To achieve a high level of comfort in residential, public and industrial housing, which presupposes qualitative and quantitative growth of the 
range of services in heat supply (heating, hot water supplies), ventilation and cold water supply (conditioning); to achieve a level compatible with European quality standards in supplying the public and the other sectors of economy with this range of services at a reasonable, affordable price;

- To raise the level of maintenance of heat supply systems drastically using innovative, highly-effective technology and sophisticated equipment;

- $\quad$ To reduce unproductive heat losses and wasteful use of fuel;

- To ensure manageability, reliability, safety and economic efficiency of heat supply;

- $\quad$ To reduce the negative impact on the environment.

Large-scale aims such as these cannot meet the deadline of 2030 without a clearly defined strategy of attaining the targets set, without the complex of technical, economic and organizational activities, as well as without understanding the sources of financing. It is obvious that the necessary organizational and economic mechanisms ought to be developed and initiated in the shortest time possible. This very document, however, fails to define the order of implementing such complex measures that would account for the existing contradictions and problematic areas within the system.

Today, for instance, it is practically impossible to attract private investment to the sphere of heat supply because of low efficiency of investment projects and overall unprofitability of heat supply companies, which, in its turn, is connected with great heat losses in production and delivery, as well as with the tariffs kept at low levels.

Optimizing the tariffs as a system is a very complicated issue, since heat supply has to remain affordable to the consumer, including the general public.

Writing out the requirements for the equipment and raising the energy efficiency of individual housing alone will not improve the feasibility of heat supply, as long as heat supply companies have no resources to finance energysaving activities. (The standard practice is to introduce economy at the cost of the heat tariffs).

\section{Proposed organizational economic mechanism}

To solve the tasks set in the Economic Strategy, it is essential that we create an organizational economic mechanism to manage the heat supply systems. This mechanism will include the following elements of primary importance:

- The creation of a specialized federal structure to deal with the issues of heat supply exclusively. At present, the sphere of supply on the federal level is supervised by several institutions, without a centralized unit for decision-making;

- The implementation of a unified, specialized federal system for collecting and processing data on production and consumption of heat energy across Russia as well as in different federal subjects;

- Accepting a range of federal programs aimed at raising the level of validity of the information gained and at improving the controllability of heat systems, and in particular, accepting programs of installing 
metering devices at the sources of heat energy, as well as programs of financing the development of heat supply schemes.

- The development of the methodological basis and economical mechanism to attract private investment to the projects, aimed at raising the energy efficiency of production, distribution and consumption of energy, while observing the criteria for the availability of the heat supply service for socially unprotected customers.

- Defining the criteria for governmental involvement in the projects of the heat supply sphere, which pose as insufficiently profitable for private investment, but still are necessary to improve reliability and quality of heat supply.

\section{Principles of complex reformation of the heat supply system}

The economically feasible program for reforming the system of heat supply should be based on the following principles:

1) The principle of investment attractiveness of the projects for private investors that are included into the program;

2) The principle of availability of heat supply services for consumers at all the stages of the program realization;

3) The principle of raising the quality and reliability of heat supply whilst the program is being implemented;

4) The principle of governmental involvement in financing the projects that are not effective economically, but are still essential to realize the program.

In heat supply systems fees reduction can be carried out either through raising the energy efficiency of production and energy resources delivery or through reducing the amount of consumption (reducing heat losses in constructions and heat networks)

The complex program to reform the heat supply system of the region, of the municipality (further referred to as CPRHS) should account for the simultaneous realization of energy saving for the consumer, in heat network organizations, and also account for the projects of loss reduction during heat energy production and delivery.

\section{Main stages of the development of CPRHS}

The development of CPRHS presupposes several stages (as illustrated by the example of CPRHS of the municipality).

\subsection{First stage}

Qualitative assessment of the potential possibility to reduce heat energy consumption by all the consumers of a municipality; defining a minimally realistic amount of end consumption that would be attainable at the present-day level of energy-saving technologies. 


\subsection{Second stage}

Collecting, systemizing and analyzing the information on the pre-planned investment projects aimed at raising the efficiency of all the participants of the heat supply process in a municipality: heat generating ones, heat networks and consumers. On every investment project there is an express analysis to be made, which allows defining the maximum value $I_{0}^{\max }$ of investment into the given project. This value can be used as a selection criterion for the projects to be later included into CPRHS, if the budget is limited or inaccessible.

The author states in the papers [2], [3] that the value $I_{0}^{\max }$ for heat supply companies can be calculated by the following expression.

$$
I_{0}^{\max }=\Delta C_{0} \cdot \frac{A}{\left(1+t_{a} \cdot A / 2\right)},
$$

where $\Delta C_{0}$ is the annual cost-saving as a result of the project, $\mathrm{n}_{\mathrm{a}}$ depreciation period, $t_{a}$ is the property levy, $r_{r}$ is the real interest rate, and $A$ is the complex $\frac{1-\left(1+r_{r}\right)^{-n_{a}}}{r_{r}}$.

For consumers the value $I_{0}^{\max }$ can be calculated by the following expression.

$$
I_{0}^{\max }=T_{0 b} \cdot Q_{b} \cdot(1-k) \cdot\left[\alpha_{\mathrm{var}} \cdot A+B\right],
$$

where $T_{0 b}$ is the base tariff for heat energy, $Q_{b}$ is the base volume of consumption, $\mathrm{k}$ is the coefficient of reducing heat consumption from the base level, $\alpha_{\text {var }}$ is the rate of variable costs in the heat energy tariff; $n$ and $n_{1}$ is the payback period and the amount of years for the realization of the project of heat consumption reduction. Therefore, complex $A_{l}$ :

$$
A_{1}=\frac{1}{n_{1}} \cdot\left(\frac{1}{r_{r}}-\frac{n_{1}}{r_{r} \cdot\left(1+r_{r}\right)^{n_{1}}}+\frac{1-\left(1+r_{r}\right)^{-\left(n_{1}-1\right)}}{\left(r_{r}\right)^{2}}\right),
$$

complex $B$ :

$$
B=\frac{1-\left(1+r_{r}\right)^{-\left(n-n_{1}\right)}}{r_{p r}}
$$

Whenever it appears to be necessary to implement priority projects irrespective of their cost, CPRHS can also include the projects whose cost by far exceeds the maximally allowed value for private investment. In this case, when the financing plan for CPRHS is being developed, it is essential to foresee the usage of a certain part of the budget.

As the author shows in paper [4], the most efficient way of setting tariffs on heat energy from the point of view of their availability to the consumer during the realization of investment energy-saving projects is the scheme of maintaining cost-saving within the tariff for the payback period. 


\subsection{Third stage}

All qualitative indicators in dynamics are calculated: the volume of consumption, the economy of cost per unit, the tariffs for producing and delivering heat energy at fixed prices.

\subsection{Fourth stage}

The final model is worked out and analyzed to satisfy all conditions, the potential (maximal) payment economy for the consumer is calculated, as well as the cost-saving coefficient for the consumer, optimal for all the participants. In other words, a system of equations is solved.

1) Potential payment economy for the consumer in year $\mathrm{j}$ :

$$
\Delta P_{j}=Q_{\text {cons }}^{0} \cdot T_{\text {cons }}^{0}-Q_{\text {ncons }} \cdot T_{\text {consj }} \geq 0 \text {, with } \mathrm{j}=1, \ldots, \mathrm{n},
$$

where $Q_{\text {cons }}^{0}$ and $T_{\text {cons }}^{0}$ is the starting level of heat energy consumption and the starting tariff for heat energy for the consumers accordingly, and the tariff in year $\mathrm{j}$ is a sum of the tariff for production and the tariff for the delivery of heat energy:

$$
T_{\text {consj }}=T_{\text {consj }}^{\text {prod }}+T_{\text {consj }}^{\text {netw }} \text {. }
$$

The calculations for cost-saving are made with adjustments to the growth of the heat production tariff, whenever consumption volume is reduced.

2) Criterion for the program's efficiency for a heat-generating company:

$$
N P V_{\text {prod }}=\sum_{j=0}^{n}\left(\Delta C F_{j}^{\text {prod }}-I_{j}^{\text {prod }}\right) \cdot k_{\partial j}>0,
$$

where the amount of cash flow in year $\mathrm{j}$ is the following:

$$
\begin{aligned}
\Delta C F_{j}^{\text {prod }}= & \Delta C_{j}^{\text {prod_vat }}-t_{a} \cdot I^{\text {prod }}{ }_{r e s j}- \\
& -t_{p} \cdot\left(\Delta C_{j}^{\text {prod }}-t_{a} \cdot I^{\text {prod }}{ }_{r e s j}-C^{\text {prod }}{ }_{a}\right)-T_{\text {vatj }} .
\end{aligned}
$$

Both here and in the expression (10):

$\Delta C_{j}^{v a t}$ is the value for the amount of resource economy in year $\mathrm{j}$ of realizing the project with VAT, calculated for the volume of end consumption of heat energy $Q_{\text {consj }}$;

$t_{a}$ and $t_{p}$ are property tax rates and profit tax rates, consequently;

$I_{\text {resj }}$ is the residual cost of the equipment installed during the realization of the project in year $j$.

$C_{a}$ are annual expenses on the depreciation of the equipment installed during the realization of the project

$T_{v a t j}$ is the value for the amount VAT entering the budget, which appears as a result of the project realized in year $j$. 
It is noteworthy that the value for the amount of interest rates paid out on the credit is not included into the calculation for $C F_{j}$, because the cost of capital is considered later in the discounting operation;

$I_{j}$ is the value for investment in year $j$;

$k_{\partial j}$ is the discounting coefficient in year $j$.

3) The criterion for assessing the effectiveness of the program for a heat network company:

$$
N P V_{n e t w}=\sum_{j=0}^{n}\left(\Delta C F_{j}^{n e t w}-I_{j}^{n e t w}\right) \cdot k_{\partial j}>0,
$$

where the amount of cash flow in year $\mathrm{j}$ is the following:

$$
\begin{aligned}
\Delta C F_{j}^{\text {netw }}= & \Delta C_{j}^{\text {netw }}{ }_{-}^{\text {vat }}-t_{a} \cdot I^{\text {netw }}{ }_{r e s j}- \\
& -t_{p} \cdot\left(\Delta C_{j}^{\text {netw }}{ }_{j}-t_{a} \cdot I^{\text {netw }}{ }_{r e s j}-C^{\text {netw }}{ }_{a}\right)-T_{\text {vatj }} .
\end{aligned}
$$

4) The criterion for assessing the effectiveness of the program for investment into the energy services contract for the consumers:

$$
N P V_{\text {en_serv }}=\sum_{j=0}^{n}\left(\Delta P_{j} \cdot\left(1-k_{\text {cons }}\right)-I^{e n_{-} \text {serv }}{ }_{j}\right) \cdot k_{\partial j}>0 \text {, when }
$$

where $0 \leq k_{\text {cons }} \leq 1$ is the coefficient for distributing payment economy over consumers. When the value of the coefficient equals 0 , all the economy goes to the investor; when the coefficient equals 1 , it goes to the consumer.

5) The criterion for assessing the effectiveness of the program for consumers:

$$
\Delta P_{j} \cdot k_{\text {cons }}=k_{\text {cons }} \cdot\left(Q_{\text {cons }}^{0} \cdot T_{\text {cons }}^{0}-Q_{\text {consj }} \cdot T_{\text {consj }}\right) \geq 0 .
$$

\subsection{Fifth stage}

The condition for the availability of heat supply service to the consumer and to the general public, in the first place, leads to the necessity of developing such program of heat supply reformation that do not lead to the increase in pay for the consumer above the usual level of inflation (the increase of so-called "limiting indices") Because of this, the realization of capital-intensive investment projects in the sphere of heat supply in most municipalities - as practical experience demonstrates - is impossible without attracting budget finance to a smaller or greater extent. To provide the conditions for maximum budget efficiency, the optimal scheme for budget investment should be defined looking at the maximum possible value for private investment, with value NPV positive for all the participants of CPRHS of the municipality, and should also be based on the concrete scheme for returning private investment made into the given projects. 


\section{Development of the optimal scheme of budget financing}

The cashflow model for the development of the optimal scheme of budget financing into CPRHS of the municipality can be built upon the criterion of network future value (NFV). The method for assessing investment efficiency, as based upon this criterion, was described by the author in detail in $[5,6]$.

The expression for the criterion NFV looks a follows:

$$
N F V=\sum_{j=0}^{n}\left(\Delta C F_{j} \cdot I_{p j}-R_{j}-D_{j}\right) \cdot\left(1+r_{\partial} \cdot\left(1-t_{p}\right)\right)^{(n-j)}>0,
$$

where $\triangle C F_{j}$ is additional cash flow after realizing the project with fixed prices (with prices at ' 0 ' time point), defined by (8);

$I_{p j}$ is the price index at the time of $j$;

$R_{j}$ is the interest rates paid out on the investment credit at the time of $j$

$D_{j}$ is a part of the capital of the investment credit paid out at the time of $j$;

$r_{\partial}$ is the interest rate on the deposit per unit.

The expression (13) helps to define the missing sum of the budget, necessary to cover to cash flow gap, at any time; it also accounts for the possibility of gaining additional effect from depositing temporarily free cash on the account. When the value NFV is calculated for a longer term $(n=20-30$ years $)$ and CPRHS of the municipality is effective enough, it is possible to define the possibility of returning not only private investment but also budget one, either fully or partially; it is also possible to work out an optimal financing scheme for the projects within the complex program and to assess the overall efficiency of the planned process of reforming the heat supply system of the municipality.

In the end, based upon the model built, a complex program of reforming the heat supply system of the municipality that would meet all the criteria of economic efficiency and satisfy the conditions to never exceed limiting indices of public payments for heat supply is worked out and developed.

\section{Approbation of the proposed model}

Approbation of the model developed was carried out by the author with the sole aim to assess the economic efficiency of CPRHS of a certain municipality in Sverdlovsk region. Within The framework of CPRHS enabled the analysis of the investment program of a heat supply company, which included a set of largescale energy-saving activities; based upon CPRHS, cost saving was calculated and investment payback period defined, after which the consumer tariff can be reduced by the value of the savings made.

Besides the program of energy-saving for a heat supplying company, and complex program to reform the heat supply system of the given municipality, the realization of a large-scale investment project is provided for, which is aimed at reducing the consumption of heat energy by the end consumer. An assessment of 
the possibility for such reduction was performed through façade and roofing insulation, through the replacement of windows in residential housing, in the houses of budget and commercial consumers of heat energy; large-scale indicators for capital investment into these activities were calculated. Consolidated, the figures appear to be the following: the term for realizing the insulation program is 8 years, the consumption of heat energy after the insulation is 95.4 thousand Gkal/year (the index for heat consumption reduction is 0.545 ), the total investment into insulation activities is 920 million roubles without VAT. The maximum amount of private investment that might be attracted to finance this program can be calculated by the expressions (2)-(4). This value constituted 625.4 million roubles, with the payback period of 20 years and the share of variable costs of a heat supply company of $71.2 \%$.

Further calculations were made on the condition of preserving $20 \%$ payment economy for the end consumer to raise the level of their interest in the complex program to reform the heat supply system of the municipality. Preserving a part of the payment economy for consumers called for the reduction of threshold value of the amount of private investment, which are attracted into the program of energy-saving for consumers, down to 500 million roubles without VAT. Therefore, the necessary amount of the budget, attracted to the program, was 420 million rouble (as calculated in 2010).

Summing up, the model suggested allows the following:

- Defining the economically optimal balance between private and budget investment in the program of reforming the system of heat supply;

- Calculating the time period, by the end of which payments for heat energy can realistically be reduced for the general public;

- Securing the affordability of the heat supply service during the realization of the program for the socially unprotected customer.

\section{References}

[1] Strategy of the power sector of Russia up to the year 2030. Passed by the bill of the Government of the Russian Federation on 13.11.2009 № 1715-p. (Энергетическая стратегия России на период до 2030 года. Утверждена Распоряжением Правительства Российской Федерации от 13.11.2009 № 1715-p).

[2] The methods for defining limiting values of private investment with external financing of energy and resource-saving projects in heat supply service. Yulia Munts// Industrial power sector, 2011, № 8, pp. 2-6. (Методика определения предельной величины частных инвестиций при внешнем финансировании энерго- и ресурсосберегающих проектов в теплоснабжении./ Мунц Ю.Г.// Промышленная энергетика, 2011, № 8, c. 2-6.)

[3] The assessment of the possibility of attracting private investment into the complex projects of reducing heat energy consumption. Yulia Munts// Industrial power sector, 2011, № 11, pp. 2-6. (Оценка возможности привлечения частных инвестиций в комплексные проекты снижения 
потребления тепловой энергии./ Мунц Ю.Г.// Промышленная энергетика, 2011, № 11, с. 2-6.)

[4] Methodology specifics of accounting the scheme for investment return, given in the tariffs for heat energy production, with external financing of energy-saving resources. Yulia Munts // Industrial power sector, 2011, № 6, pp. 17-21. (Методические особенности учета схемы возврата инвестиций в тарифах на выработку тепловой энергии при внешнем финансировании энергосберегающих проектов./ Мунц Ю.Г.// Промышленная энергетика, 2011, № 6, с. 17-21.)

[5] Methodology specifics of profitability analysis of energy sector investment. Yulia Lekomtseva.// Industrial power sector, 1996, № 12, pp. 2-6. (Методические особенности анализа рентабельности инвестиций в энергетику./ Лекомцева Ю.Г.// Промышленная энергетика, 1996, № 12, c. 2-6.)

[6] The analysis of efficiency of investment projects based on the operating cashflow. / Yulia Munts// Scientific Review, 2013, № 2, pp. 292-294. (Анализ эффективности инвестиционных проектов на основе операционного денежного потока./ Мунц Ю.Г.// Научное обозрение, 2013, № 2, с. 292-294.) 